\title{
Wîcohkamakew - A qualitative description of parents, perinatal clinic staff, and mentor Elders experiences of a Nêhiyawi (Cree) community- derived Elders Mentoring Program: Findings from the ENRICH study
}

Richard Thomas Oster ( $\sim$ roster@ualberta.ca )

University of Alberta https://orcid.org/0000-0003-0657-9263

Ellen Toth

University of Alberta

Rhonda Bell

University of Alberta

Research article

Keywords: Community-based participatory research; Health care providers; Indigenous population; Mentoring; Prenatal care; Qualitative research

Posted Date: November 8th, 2019

DOl: https://doi.org/10.21203/rs.2.17085/v1

License: (c) (1) This work is licensed under a Creative Commons Attribution 4.0 International License. Read Full License 


\section{Abstract}

Background: Responding to concerns over perinatal health risks and adverse outcomes, a communitybased participatory research (CBPR) partnership was established in collaboration with a large Nêhiyawi (Cree) community in Alberta and university-based researchers. An Elders Mentoring Program was designed and implemented to provide additional support for pregnant women and their partners. Our objective was to understand the collective experiences of those involved in the Program. Methods: We conducted a qualitative description with the principles of CBPR as an over-arching framework. A total of 14 qualitative interviews were conducted with parents utilizing the Program, perinatal clinic staff helping to facilitate the Program, and mentor Elders that engage with parents as part of the Program. Community Advisory Committee meeting notes were also used as data. All qualitative data was analyzed using content analysis. Results: The Program helps pregnant women and their partners by fostering enhanced support networks as well as improved cultural security within the clinical environment and learning among healthcare staff. A sense of intergenerational fulfillment and enjoyment among those involved in the Program was common, and was underpinned by genuine, collaborative relationships Conclusions: Successful implementation of a community-derived prenatal Elders Mentoring Program is possible with significant community collaboration.

\section{Background}

Health inequities between Indigenous and non-Indigenous populations are notably prominent when examining maternal and infant health risk factors and outcomes $[1,2]$. These are thought to be rooted within the historical trauma resulting from colonial policies of cultural genocide and domination that continue to unfold and ravage Indigenous populations [3-5]. Unsurprisingly, Indigenous communities are increasingly developing and advocating for decolonizing and grassroots initiatives as a means to improve health and wellbeing. Key recent movements, such as the Truth and Reconciliation Commission Calls to Action [6] and the United Nations Declaration on the Rights of Indigenous Peoples [7], among others, substantiate the need for such initiatives. Moreover, current research indicates pregnant Indigenous women and their partners may benefit from culturally appropriate services, flexible prenatal care approaches, traditional pregnancy knowledge and healing practices, and enhanced support networks $[5,8-10]$.

With this in mind, and combined with a community-voiced need for improved pregnancy health and outcomes, an Elders Mentoring Program was developed and implemented to provide additional help and support for pregnant women and their partners from a large Nêhiyawi (Cree) community. In this article we describe and qualitatively evaluate the Program, which is one part of a larger and ongoing communitybased participatory research (CBPR) partnership. The term wicohkamakew was chosen intentionally for this article by Elders from our research partnership community. Wicohkamakew can be translated as "s/he helps someone," and is a fundamental Nêhiyawi cultural value. From the perspective of our Elders, wicohkamakew captures the meaning of the Elders Mentoring Program and the findings described herein. 


\section{Objective, Overarching Approach, and Program Description}

The objective of this study was to understand the collective experiences of those involved in a community-derived Elders Mentoring Program aimed at supporting Nêhiyawi parents. This study was part of an ongoing CBPR project carried out in partnership with the communities of Maskwacîs, Alberta. The goal of our partnership is to gain an in-depth understanding of how to better support pregnant Nêhiyawi women, with the overall aim of improving perinatal-related health and pregnancy outcomes. Our collaboration with Maskwacîs is one piece of a multi-sectoral research program called ENRICH, that aims to improve maternal health in the province of Alberta. Maskwacîs is a rural community with a registered population of 16,004 and is comprised of four distinct First Nations bands: Samson, Louis Bull, Montana, and Ermineskin Cree Nations. The community is approximately $90 \mathrm{~km}$ south of Edmonton, Alberta, within the Treaty Six area of Canada.

We used CBPR for our approach, which relies heavily on an experiential and participative-knowing epistemology [11]. The theoretical basis of CBPR suggests that research developed from an outsiderexpert standpoint is typically insufficient in addressing community issues [11]. CBPR recognizes that community members best realize and understand their own context and posses knowledge and expertise that are imperative for useful research aimed at benefiting communities [12]. Respectful and considerate CBPR with Indigenous communities can lead to community-owned and viable benefits [13]. Owing to trusting and genuine partnerships, CBPR approaches include community members as experts and make certain research is appropriate, culturally sensitive, relevant, and equitable [12].

Our CBPR partnership began in 2013 with RTO (first author) spending roughly a year and a half engaging with the community. Engagement focused primarily on developing and enhancing relationships and trust, hearing from community members (including women of childbearing age), and grasping the context in which pregnant women live within the community. Subsequently, a Community Advisory Committee (CAC) was formed and a research partnership was formalized. The CAC core group consisted of several key Elders within the community, the local nurse manager, a research assistant turned graduate student from the community, and a mixed-methods researcher from the University of Alberta. Through regular cooperative meetings, the CAC guided and oversaw all stages of the research project. Staff from a neighboring Primary Care Network (PCN) and local health/social services departments, as well as other community members and Elders, were also invited to inform some of the CAC meetings as needed.

The idea of an Elders Mentoring Program was conceived within the initial CAC meetings. It was known from administrative data provided by the Alberta Perinatal Health Program that high risk pregnancies and adverse pregnancy outcomes occurred with significantly more frequency in the community than provincial averages (unpublished). In addition, the CAC expressed serious concerns over the health of pregnant women within the community. "We need to act now... the community is starving for this" (Elder) was the sentiment from our very first meeting. The CAC agreed there was no time to waste and that a 
community-derived and strength-based solution was needed immediately, with the goal of support expecting parents.

To this end, a Program was conceptualized where Elders can interact with pregnant women and their partners in the clinical setting to provide support, and ultimately to "protect every grandchild" (Elder). Each year there are roughly 300-350 births within Maskwacîs, and the majority of pregnant women from the community receive prenatal services off-reserve from the PCN in a neighbouring community where the care team is made up of primarily non-Indigenous care providers. Collaboration with the PCN was initiated and the Elders Mentoring Program was born as a potentially effective and pragmatic means to reach parents that builds on the strengths within the community.

After piloting this approach for approximately three months, the Program was expanded and re-launched. Initially, several 'meet and greet' lunches were held for clinic staff and Elder mentors to discuss the Program functioning and develop relationships. The Program was advertised within the PCN and also within the community. In March 2016, Elders began attending the PCN for half day sessions on approximately one out of two specific prenatal clinic days each week. In April 2017, with the Program was further refined such that Elders began attending each prenatal clinic day for half day sessions; approximately $30 \%$ of pregnant women from the community were exposed to the program each month at the PCN.

Elders engage with parents within the waiting area by striking up conversations, offering their support, handing out program flyers, providing healthy snacks and beverages, conducting cultural activities and displays, speaking about their experiences and traditional ways of pregnancy and childbirth, and initiating draws for free traditional moss bag infant carriers and gift cards to local stores. Those seeking additional Elder support have the option of speaking privately in a separate room. Elders voluntarily offered their support 24 hours per day and are primarily accessible by telephone.

\section{Methods}

We used qualitative description to understand the experiences of those involved in the Elders Mentoring Program. The CAC determined it was essential that the direct and unadulterated voices of those included in the Program were portrayed, and qualitative description fit well. Qualitative description is frequently used when a preliminary descriptive summary of a phenomenon is needed [14], and stays close to the words of participants to generate rich and straight descriptions with 'low-interference' data interpretation [15]. The CAC also felt a descriptive summary of the experiences of those involved in the Program could encourage future research in this area that is more theory-based.

\section{Data generation}

Two key sources of data where drawn upon, including CAC meeting notes and interviews with those connected to the Program. The data were generated beginning with our first CAC meeting in June 2014 and ending with the last qualitative interview in October 2017. Since the beginning of our CAC, detailed 
meeting notes were taken and were used as data. After the expanded program was operational for over a year, qualitative interviews were carried out between March and October 2017. Participants for this qualitative study were recruited using purposeful sampling to capture the perspectives of parents utilizing the Program, perinatal clinic staff helping to facilitate the Program, and mentor Elders that engage with parents as part of the Program. RTO carried out one-on-one semi-structured interviews with participants. The interviews were conducted in English, lasted up to 60 minutes, and were audio-recorded and transcribed verbatim. Participants were prompted to discuss their experience in being involved with the Program. All of the interviews were conversational and participants were encouraged to discuss any other information they felt was relevant.

\section{Data analysis}

Data analysis took place concurrently with data generation. RTO analyzed all the data using qualitative content analysis [16] and Atlas.ti qualitative computer software. Transcripts were read and re-read separately, and persistent concepts and core patterns were highlighted and categorized. The categories were similarly read and re-read, and were then carefully described in draft findings. The categories were also considered together to identify any common threads. To help refine the categories and reduce redundancy, initial findings were discussed with the CAC and members of the research team. Data collection and analysis ended when no additional insight emerged, and when the categories were well defined by the CAC.

\section{Ethics}

During the CBPR process, and design and implementation of the program, ethical issues were addressed at several levels. Ethical approval from the University of Alberta Research Ethics Board was acquired which adheres to the Tri-Council Policy Statement - 2 Research Involving the First Nations, Inuit and Métis Peoples of Canada [17]. Prior to the development of the research protocol, community approval from key stakeholders and Elders was obtained. The CAC was involved at all stages of the project, providing ethical counsel and ensuring the research moved forward in a culturally and community appropriate way. A research agreement between members of the CAC was developed and signed that outlined the purpose, overall approach, roles and responsibilities, research methods, ethical issues, dissemination strategies, and data ownership. For qualitative data generation, an information letter detailing the project was reviewed with potential participants, and written informed consent was provided prior to data collection.

\section{Rigor}

Strength and rigor were maintained by adhering to the approaches of authenticity, credibility, criticality and integrity of data collected $[18,19]$. Authenticity meant taking careful consideration of the voices of participants, and was reached by purposeful sampling, participant-driven data generation and precise transcription. Credibility meant depicting a truly insider point of view, and was reached by researcher reflection on the believability of the findings and CAC review. Criticality meant being questioning of our work, and was reached by reflection on the critical appraisal of decisions made during the research 
process and the inclusion of CAC throughout. Integrity meant honesty and integrity in our work, and was reach by peer review and reflection on researcher bias. Rigor was further enhanced by relying upon the CBPR process and frequently seeking advice from the CAC. Finally, RTO kept a reflective personal journal throughout the research process, paying particular reflexivity to the role of being a non-Indigenous father and researcher interpreting the voices of Indigenous parents, healthcare staff, and Indigenous Elders. Reflexivity helped ensure the principles of CBPR were relied upon throughout and that the authentic voice of the participants was presented.

\section{Results}

Notes from 23 CAC meetings were included in the analysis. Six parents (five mothers and one father), four clinic staff, and four Elders took part in interviews, for a total of 14 interviews. The average age of parents was 22 years (range 17 - 34), of clinic staff was 39 years (range 30 - 49), and of Elders was 66 years (range 57 - 79). The average number of children per parent participant was three (range 1 - 8). Vivid personal reflections related to their recent experiences with the Program were shared by all of the participants. Although their stories were distinct, there were many similarities related to their experiences with the Program which are detailed in the following categories: Enhanced Support Networks, Improved Cultural Security and Learning, and Intergenerational Fulfillment and Enjoyment.

\section{Enhanced Support Networks}

Elders felt that with every pregnancy and every newborn child there is hope, and that the Program helps to foster that hope. It was recognized that all pregnant women and their partners need support, whether they are Indigenous or non-Indigenous, and that generally "the more support the better." (Clinic staff member) Some parents described having very little help and reassurance during their pregnancy, and welcomed the opportunity to get support from an Elder, through the Program. The Program was uniformly acknowledged by all participants as an opportunity for parents to receive enhanced support through their pregnancy for those that need it, first time, teenage, and younger parents especially. For instance, one first time parent expressed, "I know that maybe this Program wouldn't benefit other people, but it did for sure benefit me. I will say that." Those that tended to not engage the Program as much for in-depth support cited already having strong support systems and good access to Elders in their family and/or community.

The provision of support through the Program was multi-layered and tended to be specific to what parents were dealing with on a day-to-day basis in their lives. Elder support meant connecting on a personal level, actively listening, empowering, encouraging, validating, valuing parents as people, being non-judgmental, being kind and caring, transferring cultural and traditional knowledge, helping to mend historical traumas and foster healing, teaching parenting skills, responsibility, values, and respect, and effectively "being on their side" (Clinic staff member). Parents expressed feeling comforted knowing they could call upon an Elder if they needed to, as one described: "she would tell me that if I didn't have anybody to come with me to the labour room or if I needed her at anytime that she would be there." 
(Parent) The significance and importance of Elder support through the Program is illuminated in the following quotes:

I connect with the person, and we laugh. I tell stories. So it's all about the human connection. We know that a person is strong enough as they are, whether they're struggling, whether they're dysfunctional, shall we say. They're still powerful. And us [Elders], we go there and try to empower them in a very positive, sacred way - you know. And so, that's how I see the Program functioning there. That's my task there and it's a privilege. (Elder)

Just being open, being a positive support, and an encouragement. Because that's what I think they're missing, is someone to kind of be in their corner for them and say, 'look, I'm here for you if you need me.' I think that's really powerful for them to hear that. (Elder)

I liked seeing her when I would walk through the door. Yeah, she would always come to talk to me. I actually invited her to my house to help me put my baby in a moss bag... Just someone to talk to while I was waiting because I didn't really take anybody with me to my appointments. It's for like people that don't have the support for themselves. It felt good knowing that I had someone to talk to when I went there. (Parent)

I do hope they continue with the Program. It gives me somebody to talk to, even if it's something silly... It's nice to have someone to talk to, because my best friend bailed on me after I got pregnant... I wouldn't want to talk to some young guy about my pregnancy or my feelings. I liked the fact that I had the Elder, because it's someone who has experience with their life. (Parent)

I didn't feel judged by her. It was nice, because she approached me and I didn't have to approach her... It is difficult [being pregnant]. It is. I'm not going to lie... because people just look at me and they'll be like, 'Oh! Wow, she had a big mistake.' Or, 'someone didn't raise their kid right.' When you're sitting in that clinic and it's full, like no chairs available, full, you feel judged... like, my boyfriend works and my mom works and my sister works. And my grandma has cancer so she goes to the Cancer Society. So, there's me, leaving school, coming there, and sitting there all by myself. And I don't feel judged anymore, because I'm confident in being a mom. It makes me confident to be a mom, for sure, and that's what I like most about the Program specifically is I didn't feel any judgement from her at all. It really made me feel better. I love being there, because I didn't look alone. (Parent)

Supporting parents was described extensively by all of the participants as the crux the Elders Mentoring Program. There was agreement among all participants that the Program is providing a relevant support service that was previously lacking within the prenatal clinical setting. Many women from the community face unique and continuous challenges, especially during pregnancy, and these challenges often "fall through the cracks" (Elder) within the western healthcare system. Challenges parents may face within the community were described as a "stew of crisis" (Elder; see Table 1). In many instances, care providers are unable to provide the needed support to parents as they are generally not from the community and may not identify with the complexities faced by community members. Moreover, the lack of inclusion and 
acknowledgement of male partners during pregnancy was often identified as a gap in perinatal care. Thus, having Elders from the community that "have been there before" (Clinic staff member), understand the issues faced by young parents, accept parents "for who we are" (Parent), provide a "safe space" (Parent), and who are able to offer culturally and community-appropriate support and advice, was viewed as filling a significant gap in prenatal care, as described in the following quotes:

If I put myself in that position, and I was young, and unsure of myself, maybe my home is overcrowded, maybe I don't live in a very happy environment, because when you really face the facts there's a lot of family violence. There's a lot of domestic violence. There's alcoholism, there's drug addiction, and no one is untouched by those elements. And so we have children becoming mothers in this milieu, what more important way is there then to go there when a mother is expecting and to say: 'You know what? You're going to be okay. You're a very strong girl, and you're a good dad. You're right here and that says so much about you.' (Elder)

If they [staff] have somebody in the room that really needs a little bit of guidance, it's like, 'we have an Elder. Would you like to talk to an Elder?' And they'll come in here and close the door, and they'll sit and visit. There have been days where they were like 'I'd like to talk to an Elder,' rather than one of our therapists. You know? So it's been beneficial. Even when you get that one person that's like, 'I'm so glad she was here today,' it just make my day... Elders are great to talk to too, as far as, you know, what's available and what kind of help they [women] are needing, and where they could kind of direct them in their own kind of way. (Clinic staff member)

I guess that's the closest person I had to someone being there for me, that understands. But it was nice because um, like older - older people have their - their different ways and like their beliefs and like... Um, like they're Elders so they know, right? They know what kids shouldn't be doing and stuff and... I liked it because when I was around old people. (Parent)

I have seen a value in the Elder program. I see that the patients are maybe more willing to speak to an Elder than say, ourselves or our therapist, or our nurses, even. Even in an open space, like the waiting room area, they'll still give more information than they might in a closed door to one of our nurses. So, I see that there's value there. And I think that it's a fantastic idea. I think there's a respect for their Elder, whether it's their own family Elder, or an Elder in general. And you can see where, if they maybe weren't warm and fuzzy to say myself, they will answer that Elder's question. They have a high respect for an Elder in general... and I think once they have that attention, then the Elder could - sky's the limit... I see it, when I see the Elder sits down beside them. They put down their phones, they pay attention. It's amazing. (Clinic staff member)

There could be a whole host of things identified there [with the Program] that they don't identify in, you know, a five-minute appointment with a physician. And so, it was a good opportunity to bring those supports into place... We need somebody, you know, who speaks the language and can do this in a different way than kind of the western way of, 'okay, here's my assessment. Tell me what's wrong, and I'm 
going to send a bunch of referrals around for you, and feel good at the end of the day,' right? Like, it just needs to be done differently sometimes. (Clinic staff member)

There's nothing there for a man... And I kind of think it's helped in that sense; helped the mothers and the fathers understand each other and their roles as parents now.... Nobody thinks about the father and how it impacts his life. He does go through all of that stuff. 'Holy I made a child'. It hits him, it hits him hard, you know? But nobody recognizes it. Nobody acknowledges it... They never ask him 'are you going through postpartum depression too?' Nobody's ever asked the father that.... So I kind of think it helps them in that sense, to build a relationship that they can understand what each other is going through, and the feelings and emotions of being a parent now. And they go through the same feelings and emotions that overwhelm them sometimes. (Elder)

Table 1: Community identified challenges faced by some parents during pregnancy. 
"Stew of crisis" (Elder)

Teenage pregnancies

Childcare challenges

Transportation issues

Alcoholism

Addictions

Sexual immorality

Sexually transmitted diseases

Sexual abuse

Domestic violence

Prostitution

Lack of safe place for women and men

Political issues

Intergenerational trauma and cultural genocide

Continuous state of mourning and grief

Loss of parenting skills

Loss of responsibility, values, respect, and accountability

Limited employment options

Poverty

Illiteracy

Limited community resources

Lack of consistency in programs

Poor penetration of community programs

Lack of sex education in schools

Elder abuse

Confusing and disjointed health care systems

Racism and cultural insensitivity

Disempowerment

Gestational diabetes and pregnancy complications

Stillbirths and poor pregnancy outcomes

Food insecurity

Page 10/25 


$\begin{array}{ll}\text {. } & \text { Crowded living conditions } \\ \text { - } & \text { Gangs } \\ \text { - } & \text { Poisoned wildlife and unclean land } \\ \text {. } & \text { Suicide }\end{array}$

Improved Cultural Security and Learning

Elders believed the Program contributes positively to righting colonial and historical harms (such as residential schools and other discriminating government policies) that have eroded culture, language, values, responsibilities, etc. They described having the opportunity to rebuild intergenerational connections and pass on traditional teachings again. Therefore, supporting parents through the Program also meant allowing for opportunities for connection or re-connection to traditional cultural values and teachings surrounding pregnancy, parenting, and family. Elders felt Nêhiyawi cultural practices such as smudging, wrapping infants in mossbags, singing traditional songs, speaking the Nêhiyawi language, utilizing traditional medicines, adhering to longstanding protocols for pregnant women, attending sweatlodges, participating in ceremonies (such as the belly button, afterbirth, and naming ceremonies), and following cultural underpinnings of love, compassion, and generosity were particularly important to encourage during pregnancy. One Elder described culture during pregnancy as "bringing your body, your mind into calmness. It makes you see things clear... It just helps you stop and think, instead of reacting drastically." (Elder) Parents and Elders expressed worry about the risk of these cultural practices being lost due to the ongoing impacts of colonization, and felt that the Program offered a chance for cultural learning. It was believed that incorporating traditional culture into the pregnancy would not only provide a sense of healing, belonging, and identity to parents, but would be essential to the health of the fetus. Having Nêhiyawi culture and ways of knowing genuinely incorporated into the clinical setting through the Program was thought to contribute to improving the overall sense of cultural safety for parents. The following poignant quotes reveal the importance of cultural connection in the Program:

The culture was eroded. The values were also eroded. And there was nothing strong for people to live by anymore... The girl that is the mother today, that is becoming a mother today, is very, very disconnected from her cultural values, from her identity. And she's very removed psychologically, emotionally, mentally, physically - in all aspects of her being, she is very removed from her culture, her values, and her belief system. If you asked the present mom sitting at [the clinic] today about this, she would not relate. She would not know what happened to her. Because problems - social problems in our communities are pathologized. It's, you know, 'I'm a drunk because I'm a bad person.' Not because 'I went through the assimilation process in a very horrible way.' And so, this is why [the Program] is good, to begin to mend. Many people go through a pregnancy very scared, alienated, and feeling lost. When they feel that way, the child within them feels that emotion and internalizes that emotion. And they are not born the same way 
physiologically, psychologically, as the child that was born 30 years ago, 40 years ago. So [the Program], by what we're doing now, is kind of beginning to go back to the way that - that it was a long time ago. Those forces will work. We are the facilitators of reconnecting them to the culture... I know that it is sacred and powerful work. There is no more important work on this earth than to be part of the journey of a spirit into this world. (Elder)

Even visiting [with a male Elder at the Program] yeah, talking to him and getting a little information from him. He'd send a prayer... and that gave me confidence that the baby would be okay. The stuff we talked about, it was pretty much helpful when we did get to the hospital and stuff, knowing that he had prayed for us and for a good pregnancy... So, it was good. I enjoyed talking to him.... That's a lot of support, knowing that you have somebody to talk to, that's listening. And it was good advice on how to go about it... it helped me not to panic. Like, not to get worried or anything. Kind of made me feel calm and stuff, going into the hospital, waiting for the baby there knowing that someone listened and prayed... That was good - good experience to talk to the Elder before. (Parent)

I think it's just kind of to know that there's some of their culture here [at the clinic]. You know, to have that Elder, who's a huge part of their community, and just to know that that person's here if they need to talk about anything and answer questions... To get that little bit of history, it's always a gift to kind of get almost back to their roots. I don't know. It - there's so much, you know, and I won't say Caucasian, but there's so much of our [western, non-Indigenous] culture here [at the clinic], and to have a little bit of their own Indigenous culture here is a highlight for a lot of them. (Clinic staff member)

Participants felt the Elders Mentoring Program was advancing mutual learning between clinic staff and Elders that in turn enhances the overall cultural safety of the clinic. There was agreement across all participants that clinic staff members, from front-end employees to physicians, benefit from interacting with Elders in the Program. Elders spoke of how the clinical setting is predominately non-Indigenous and can often be plagued by superiority over Indigenous people, and how the Program helps parents to feel that they are just as good as everyone else and encourages them to be proud of their culture and who they are. Clinic staff members were interested in learning more about the history, culture, and perspectives of the community, and felt the Program offered the opportunity to do so. Participants described how the Program allowed for communication, trust, and relationships to develop authentically over time that ultimately created a safe space for learning and understanding, as shown in the following quotes:

They're just now catching on. Modern day medicine is just now catching on as to why it's important to, they call it swaddling. Us, we've been doing it for centuries. I don't know if they'd realize that, 'cause they're white people. They don't know, you know? And so... but our presence, no doubt, influences them. And we depend on that influence more than to say, 'You know what, I have just as much right to be here than you.' Rather than being confrontational, and negative. You know, you... go in there with the same hope that you can influence them too, because they can influence too... In the beginning [of the Program], it was kind like ah... I'm used to that. Ah, like being an outsider, and 'you don't belong here. What are you doing here?' That's the feeling I would get in the beginning here. But nowadays, it's been so good. Like I 
get coffee here... Everybody says 'Hi'. Everybody knows my name now. And... things have changed dramatically for the good... I trust people. (Elder)

The Elders were very humble, and so gracious in you know, providing education for all of the staff there. And you know, you could ask the kind of awkward questions. You could talk about protocol. 'Cause for a lot of people, um, a lot of employees outside of - you know, working directly with First Nations communities, they don't necessarily get the cultural sensitivity training, the cultural competency training and then, even if they get some of it, they're sometimes scared to ask, for fear of offending. (Clinic staff member)

It is just such a great thing to - even for us to learn about... Even asking them about like their own families, and grandkids... We've talked about moss bags and she's shown us how to do the moss bags. Personally, I've always wanted one when I was pregnant with my kids. But, I guess it's not something you buy. It's something you're given, which is really awesome... On the clinical side - you know, what can we do to make it better and how can we make this work, and just feeling part of that team, you know, to make everything work a little bit easier, you know, has been really educational. They're so very approachable. If we have any questions they're more than happy to answer. (Clinic staff member)

I continued to learn - even the simplest things, and up to including last Thursday, when I was speaking with one of the Elders. I was - spoke to her about if it would be offensive to the community if I took the word kokôm (grandmother) as - 'cause I think it's a great name. It feels good off the tongue - do you know what I mean? When I turn into a grandparent - and she said, 'Absolutely not. That would be an honour to us, because' - and then, she went on to tell me a little bit - each vowel sound has a different protector. I learn something every time...They're super open to those types of questions. Whereas I'm kind of cautious. 'Would it be offensive if' - ? They're like, 'No, no. Let's roll with this.' And then, they don't just say yes or no. They follow that up with more information. It's fantastic. So I definitely learn from those Elders every time they come in. And I mean it's not just pre-natal questions. They have a whole ceremony for when a girl gets her first period. I had no idea how that went. (Clinic staff member)

Parents differed in their receptiveness to cultural support. On one hand, some parents hoped the Program would grow to involve more cultural activities (such as sewing, beading, and smudging in the clinical setting) and include younger people from the community that understand the culture to work with the Elders to support parents. However, not all of the parents were open to learning more about Nêhiyawi culture during the pregnancy, and Elders and clinic staff were mindful to not impose cultural beliefs upon those that were not interested in learning:

Once you have your child, it's a life changer. I try and explain... The goal of this Program is to support the young moms with whatever support they need and that doesn't necessarily mean cultural support... I don't try and preach to somebody. I just ask them well, how they feel. (Elder)

I think that connection to culture for a lot of people is important, and as - you know, non-Aboriginal people, we need to be respectful of that, right? And there are patients coming through the door that, you 
know, it wasn't of interest to them. They weren't - they didn't identify closely with their culture. And so, we could never make the assumption that people a hundred percent wanted it [cultural support] or people a hundred percent didn't want it. The whole point was to offer a choice. You know, and so it was important to have that piece in place there, so that people had more choice. (Clinic staff member)

\section{Intergenerational Fulfillment, Enjoyment, and Collaboration}

When asked about their personal experience of being involved in the Program, all of the participants repeatedly described feelings of fulfillment and satisfaction through taking part. Several clinic staff members described an enhanced sense of accomplishment in their work with the addition of Elders that were able to fill a gap in care that ultimately lead to a more cohesive and holistic clinical environment. Similarly, parents were contented after visiting with Elders in the Program and were often gratified given the opportunity to learn from Elders about pregnancy and parenting in a way they felt was relevant. Some parents discussed feeling pleased that they were able to incorporate more of "who we are as First Nations people" into their pregnancy as a result of interacting with the Elders in the Program, and that this would benefit their babies. One mother explained further that her sense of identity and that of her mother as well, was validated by talking with an Elder in the Program:

She [Elder] made me feel good about who I am... And the Elder was nice and even my mom got along with her great. And... my mom's not really the person to get along with someone good, but I'm surprised they actually sat down for like probably about two hours, an hour and a half. While I was at the clinic, I went through my whole appointment. They were still talking and laughing. I even left and I had to come back for her because that's how long they talked... It was good, because my mom got to talk to someone too, right? Even if it wasn't about like, the pre-natal clinic or whatever. It was just someone to talk to her, because my mom doesn't know who to talk to, right? She likes Native Elders, because she... she's going to become one, right? So... she - she likes to learn about that stuff... It benefitted her a lot too. My mom was really happy that day and so was I. (Parent)

Elders in particular described at length the fulfillment they felt through participating in the Program. Partnerships with clinic staff members had evolved such that they felt a part of the team. Being involved in the prenatal journey of parents to "help bring life into the world" (Elder) offered an especially strong sentiment of pleasure through giving back to their community in a meaningful way. Elders believed that their support was part of overcoming the challenges faced within the community by reconnecting parents to the "many strengths" (Elder; see Table 2) that exist also within community as well. The following two quotes help illuminate their sense of fulfillment:

The feeling when a person goes to the gym and they're done and they've had a really good workout, the finish of a long project, all those feelings that surface as a result of doing something powerful and positive, that's the feeling I get. And I impact a lot of people, and so do you, and so do all the participants [Elders facilitating the Program]. You know, so already there's a little ripple effect out there, about the goodness of the Program. You know and for them - the moms - they leave there with a good feeling, knowing that there's a support here. Knowing they're not alone. (Elder) 
For me it was, it gave me a satisfying feeling of, actually passing on my knowledge to someone else, a young adult, and young parents. I felt satisfied doing it and I, and I actually felt useful that I actually shared my knowledge with someone... Now it's just like young girls are asking like 'which Elder is here today?' They're asking that now. (Elder)

Table 2: Community identified strengths available within the community for parents during pregnancy. 


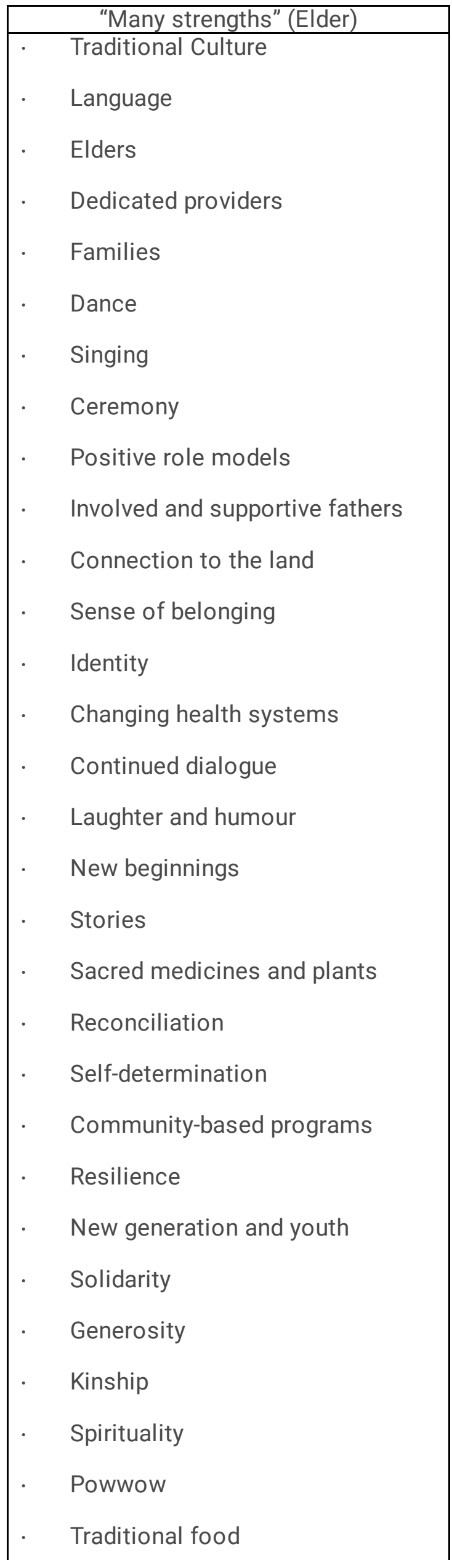

Page 16/25 


\begin{tabular}{ll|}
$\cdot$ & Friends \\
$\cdot$ & Sharing \\
$\cdot$ & Pride \\
Compassion and love \\
Medicine wheel \\
Drumming \\
Regalia
\end{tabular}

The Elders also discussed feeling fulfilled through the Program as it contributed to their own continued healing from historical traumas they had experienced in the past as a result of colonization. Several of the Elders gave in-depth and detailed accounts of their own experiences related to colonization including residential schools, foster homes, racism and discrimination, and poverty to name a few. They described how these experiences have, in many ways, hindered their ability to carry out their roles as Elders in the community during certain times of their lives. Elders shared how the Program contributes to restoring their roles, provides a renewed purpose in life, and "gives a reason to keep on going." (Elder) Specifically, being a mentor to younger parents compelled some of the Elders to look at themselves in a more honest way, open up more to others, and make positive changes so that they were better able to care for or help others. One Elder in particular explained the personal impact of the Program:

I get to talk to young men, young women. I like what I do. I hopefully can continue. When I first started, I was kind of nervous. It made me feel... like nosy or something - Like I shouldn't even be talking to this pregnant woman. That's how I felt in the beginning... But the further along we go, I I I find I'm talking to anybody now. It has just opened up my eyes. Like I was probably almost a recluse... I used to just stay home. But getting asked to be involved in this, I've thought about it a lot. I read a few chapters of books here and there and... I'm not saying I'm an expert at it now, but I'm - I'm learning and I enjoy what I'm doing. (Elder)

Finally, the participant's personal experiences of being involved in the Program also included feelings of happiness and enjoyment, and optimism about the future of the Program. For instance, the Program brought more laughter and fun into the clinic and participants felt the laid back and personal approach of the Program allowed them to have more enjoyable clinic experiences. Moreover, having Elders in the waiting area where patients arrive and are inclusive of all families, Indigenous or non-Indigenous, led to a more cheerful and welcoming environment that many of the participants described enjoying. The following quotes show the sense of enjoyment achieved through the Program:

I think we're at a point where it's really running well. It's always good to see them [Elders] when they're here. They're good people. Yeah, really good people... The Elders enjoy there time here and so do we. We 
really do... It just reflects when they come in and they're just so eager and ready to help and it's nice for everyone. We like it, it's really good. (Clinic staff member)

They're [mothers] beautiful. They - they're just - they're just so happy that we go and sit beside them, and introduce ourselves. And just make them feel more comfortable. At first they're kind of like - they just kind of sit there. And - because we live in a very impersonal world as well, you know? And so, they have to make up their mind - 'Oh yeah, this is... Ah, there - I - I'm getting positive vibes from this person.' And then it opens them up. And we start talking. And we laugh. (Elder)

She was a really, really nice lady though. It was nice to be able to just, you know, to laugh in that place. And that really made me - me the most happy... Yeah. I really enjoyed it. She actually just came and sat down with - and I mean, just started a nice conversation. (Parent)

I said those words just for laughs, you know. For laughs, yeah. Like it's... at the moment, I don't want to kill their moment and say, 'You're going to do this, you're going to do that.' But it - you talk to them slowly and just have fun. Tell them a joke every now and then. (Elder)

Reaching out to the young mothers, young parents, I just appreciate it. You know, I enjoy what I'm doing. At the clinic, I just enjoy the staff. 'Cause when I walk in there, I just introduce myself. And I tell them I'm here. The staff is really nice. I really appreciate their - you know, their acknowledgement... Oh, they all they always say they look forward and will say to me "you can come in anytime you want to." The staff there know - they see me. You know, talking and ah - or they - they greet me, you know. They know who I am. And I know who they are. And we greet each other with a hug. I enjoy what I'm doing. It has helped me... And my question is to the mothers, about me being there for them, and they've said that they've enjoyed it. It has been good. Why I keep saying I enjoy is that it's a time for me to meet people, to meet these mothers. 'Cause I know some of them, you know, from the past (Elder)

It was clear from the participant's stories that fulfillment and enjoyment were predicated upon the authentic relationships that were developed through the Program and the enhanced collaboration that ensued between Elders, healthcare staff, and parents. There was a belief among many of the participants that the common goal of healthier pregnancies was bringing individuals that were previously worlds apart, together, as one Elder commented: "We're talking - we're dealing about life - with life...We need to come together."(Elder). Coming together and evolving into a teamwork environment took time. Long seeded rifts that exist between Indigenous and non-Indigenous communities were described, as were initial feelings of trepidation as the Program was implemented. The continued and consistent presence of the Elders through the Program ultimately allowed for participants to feel comfortable with one another, for stereotypes to be deflected, and for genuine and trusting relationships to emerge. The Program, and especially the relationships developed, were described as having come "leaps and bounds from the start". (Clinic staff member) These relationships were crucial in the successful functioning of the Program and sincere collaboration allowed for the positive impacts described in the aforementioned themes to ensue. Participants spoke of how the relationships between staff, Elders, and parents have grown: 
I was here before the whole program started. So we've kind of... grown into that... to where we are now, which is great. It's a good clinic. And again, it's - it's been kind of an ongoing - it's - it's been a process. So I think it's still just kind of a bit about progressing over time. Still just a little bit of a - of a journey, to get that to - to that place where we work great together... And now l've seen a big growth with the Elders and the staff that has improved a lot since day one. (Clinic staff member)

In the beginning, it was kind of a... like a... I - I'm used to that. Ah, like a... outsider, you - you don't belong here. What are you doing here? That's the feeling I would get in the beginning here. But nowadays, it's been so good. Like... I get coffee here when the... everybody says, "Hi." Everybody knows my name now. And... things have changed dramatically for the good. I can walk around, and I leave my... leave my jacket over there. I trust people... I have nothing... anything negative about them. I like their... their response. They're always... they welcome me when I walk in. (Elder)

\section{Discussion}

The Truth and Reconciliation Commission of Canada Call to Action 22 specifically states "We call upon those who can effect change within the Canadian health-care system to recognize the value of Aboriginal healing practices and use them in the treatment of Aboriginal patients in collaboration with Aboriginal healers and Elders where requested by Aboriginal patients" [6]. This study provides rich qualitative evidence supporting this Call to Action and substantiating the need for reconciliation in healthcare through involving Indigenous Elders. Western science and medicine rarely formally acknowledge and appreciate Elders expertise within healthcare systems and organizations. Nonetheless, Elders are respected and esteemed as a result of their lived experience, cultural connectedness, leadership, knowledge, wisdom, benevolence, humility, perseverance, commitment, helpfulness, and so on, and accordingly play a vital role in the health of Indigenous populations [20]. Through a collaborative partnership, our Elders Mentoring Program recognizes the expertise of Elders as a major strength of the community, and incorporates them into a perinatal clinical setting.

To our knowledge, ours is the first study examining the inclusion of Elders in the perinatal care of Indigenous patients. Only a few other published studies have explored Indigenous Elder programs for other specific health conditions and settings. For instance, Elder-facilitated health circles focused on traditional health teachings can help to increase patient self-determination over their healthcare and ease barriers to both western and traditional healthcare according to urban Indigenous qualitative participants from Vancouver, British Columbia [21]. Involving Elders in psychiatric care for Indigenous patients within the Saskatoon, Saskatchewan area led to statistically significant decreases in self-reported rates of domestic violence [22]. More recently, qualitative interviews with Indigenous patients at an inner city primary care clinic mental health program suggest the inclusion of Elders in their direct care has a wide range of benefits on mental wellbeing [23]. Specifically, Elders contributed to creating a safe space for patients to heal, strengthening cultural identity and belonging among patients, fostering trusting relationships that allowed patients to open up more, helping patients cope better with loss, and engaging patients in ceremonial and spiritual dimensions of care and wellbeing [23]. Consistent with theses 
previous studies, our research shows that incorporating Elders into western perinatal care may fill a number gaps in care by attending to several unmet needs of pregnant Indigenous women and their partners.

For instance, it was clear that a people may face a myriad of challenges during pregnancy resulting from the continued impacts of colonization, such as intergenerational trauma, poverty, disempowerment, crowded living conditions, ongoing grief, and domestic violence to name a few. Parents in our study expressed feeling more likely to trust, connect with, and talk to Elders about these issues than to a health professional who may not understand their context well. Mistrust and disconnection between pregnant Indigenous women and healthcare providers has been thoroughly described in other qualitative research [24-27], and are rooted in cumulative historical trauma, societal marginalization, paternalism, and rampant discrimination of Indigenous people $[4,28]$. Beyond providing a more safe and trusting space for Indigenous women and their partners to discuss and deal with their unique challenges, the inclusion of Elders also had meaningful impacts on the clinic staff members' sense of their patients' context, and of providing culturally safe care. We believe this will lead to better and more frequent interactions between patients and staff. The National Aboriginal Health Organization defined cultural safety as moving "beyond the concept of cultural sensitivity to analyzing power imbalances, institutional discrimination, colonization and colonial relationships as they apply to health care." [29] There is no shortage of research calling for improved cultural safety for Indigenous patients in healthcare settings, particularly perinatal settings [8, 25, 30-32]. Our findings suggest that consistent Elder presence in perinatal care offers a novel opportunity for ongoing experiential and reflective cultural safety learning for staff as opposed to the often one time, limited, and unidirectional cultural sensitivity trainings typically offered that tend to focus on cultural differences [33].

In addition, interacting with Elders allowed patients ongoing opportunities to connect and re-connect to traditional Nêhiyawi cultural principles and philosophies that are pertinent to pregnancy and raising children. An accumulating body of research indicates that Indigenous patients, including pregnant women and their partners, want and need Indigenous culture and language incorporated into health care practices in a meaningful way $[8,24,25,30,32]$. In our study, healthcare staff also recognized the critical importance of cultural connectedness for the health and wellbeing of many of their Indigenous patients, and welcomed the opportunity for Elders to be the facilitators of culture within the clinic. Our findings add to those of others suggesting positive associations between cultural connectedness and Indigenous health, wellbeing, healing, self-determination, belonging, knowledge, empowerment and self-esteem, and identity $[21,23,34-37]$. Cultural interventions in relation to mental health and addictions have been studied far more in comparison to other health conditions, particularly pregnancy-related health. For instance, in the treatment of addictions among Indigenous populations in North America, culture-based interventions have been shown to improve patient spiritual, emotional, mental, and physical wellness, as well as decrease or eliminate substance use problems in many instances [38].

Our Elders Mentoring Program also helped to fill other noted gaps in perinatal care. The Program proved particularly helpful in supporting younger and teenage mothers through their pregnancies as they may 
feel even more vulnerable, judged, and scared. Teenage pregnancies are typically more common in Indigenous populations [39], and research from suggests that teenage pregnancies lead to poorer obstetric and perinatal outcomes and necessitate culturally appropriate care [40, 41]. Moreover, opportunities to engage with Elders in the perinatal setting were believed to lead to increased inclusion and acknowledgement of male partners during pregnancy in our study. Our previous qualitative work [9] and that of others [42-44] highlight the importance of including fathers more in perinatal care. The current study suggests that authentically and consistently incorporating traditional culture and Elder support into perinatal care approaches may help to support and include Indigenous men.

A key finding from our study was the sense of intergenerational fulfillment and enjoyment that the Elders Mentoring Program brought to all of those involved, and that this stemmed from relationships. This reflects the intent and benefit of CBPR approaches [11]. This finding also emphasizes the need for collaboration and partnership in attempts to improve Indigenous health, which has been suggested time and time again through recent research $[11-13,45,46]$. It is not enough to simply conduct research or provide healthcare in a "culturally sensitive way". For example, it was clear from extensive grounded theory research with health professionals that government agencies and health services and organizations need to work with Indigenous people in order to advance strategies that empower providers and staff to practice cultural safety and ultimately improve clinical interactions and patient outcomes [33]. Significant strides are now being made to make health practices and research practical and localized, rather than removed and devoid of investment. CBPR is now the accepted approach for Indigenous health-related research. Cultural safety and partnerships with Indigenous communities are now recommended by key health organizations as means of revamping our health systems and improving Indigenous health.

Our study has limitations. Given the distinctiveness of each community, any transferability of our findings to other Indigenous populations must be approached with caution. Also, our intervention and study was carried out in a rural Primary Care Network clinic and the suitability and usefulness in other more conventional care settings was not considered. This was our first attempt to understand the impact of a novel and community-based intervention, and the findings are formative. More robust evaluations utilizing context-specific indicators of impact are needed to compare Elder- and culture-based interventions with conventional perinatal and clinical care.

\section{Conclusion}

Our in-depth qualitative analysis has important implications for those involved in perinatal and maternal care with Indigenous women. Our study suggests that an Elders Mentoring Program within the perinatal clinical environment provides opportunities for enhanced support networks and improved cultural security for Indigenous women and families. The Program also provides the opportunity for meaningful cultural awareness among perinatal healthcare staff and a sense of intergenerational fulfillment and enjoyment among those involved in the Program. Genuine collaboration and relationship building were crucial to the success of the Program. The Elders Mentoring Program is community-derived, context- 
specific, culturally-appropriate and relevant, considers local determinants, and builds off of existing strengths within the community to make healthier futures for women, children and families.

\section{List Of Abbreviations}

CAC: Community Advisory Committee

CBPR: Community-based participatory research

PCN: Primary care network

\section{Declarations}

\section{Ethics approval and consent to participate}

Ethical approval from the University of Alberta Research Ethics Board was acquired. Prior to the development of the research protocol, community approval from key stakeholders and Elders was obtained. The Community Advisory Committee was involved at all stages of the project, providing ethical counsel and ensuring the research moved forward in a culturally and community appropriate way. For qualitative data generation, an information letter detailing the project was reviewed with potential participants, and written informed consent was provided prior to data collection.

\section{Consent for publication}

Not applicable.

\section{Availability of data and material}

Not applicable. The data will not be shared. Ethical approval for the study requires the data be kept in locked files, accessible only by the authors and community partners.

\section{Competing interests}

The authors declare that they have no competing interests

\section{Funding}

The ENRICH Project is funded through an Alberta Innovates - Health Solutions Collaborative Research and Innovation Opportunity team grant (RES0017751). This research also received additional funding through a Seed Grant funded by the generous supporters of the Lois Hole Hospital for Women through the Women and Children's Health Research Institute.

Authors' contributions 
RTO, ELT, RCB, and the ENRICH First Nations Community Advisory Committee designed the research project; RTO conducted the research; RTO analyzed the data; RTO wrote the manuscript and had primary responsibility for the final content of the manuscript; and all authors read and approved the final manuscript.

\section{Acknowledgements}

We would like to respectfully thank and recognize the communities of Maskwacîs and the participants of the study for generating this knowledge with us. We would also like to acknowledge the assistance of Randy Littlechild (CEO of Maskwacîs Health Services) as well as the staff at the Wetaskiwin Primary Care Network.

\section{References}

1. Sheppard AJ, Shapiro GD, Bushnik T, Wilkins R, Perry S, Kaufman JS, et al. Birth outcomes among First Nations, Inuit and Métis populations. Health Rep. 2017;28(11):11-6. 2. Shah PR, Zao J, Al-Wassia H, Shah V, Knowledge Synthesis Group on Determinants of Preterm/LBW Births. Pregnancy and neonatal outcomes of Aboriginal women: a systematic review and meta-analysis. Womens Health Issues. 2011;21(1):28-39. 3. Wright A, Wahoush O, Ballantyne M, Gabel C, Jack S. Selection and Use of Health Services for Infants' Needs by Indigenous Mothers in Canada: Integrative Literature Review. Can J Nurs Res. 2018;50(2):89-102. 4. King M, Smith A, Gracey M. Indigenous health part 2: The underlying causes of the health gap. Lancet. 2009;374(9683):76-85. 5. Wilson D, de la Ronde S, Brascoupé S, Apale AN, Barney L, Guthrie B, et al. Health professionals working with First Nations, Inuit, and Métis consensus guideline. J Obstet Gynaecol Can 2013;35(6 eSuppl):S1-S52. 6. Truth and Reconciliation Commission of Canada. Truth and Reconciliation Commission of Canada Calls to Action. Winnipeg, MN: Truth and Reconciliation Commission of Canada; 2015. 7. UN General Assembly. United Nations Declaration on the Rights of Indigenous Peoples. http://www.refworld.org/docid/471355a82.html. Accessed 02 October 2018. 8. Oster RT, Bruno G, Montour M, Roasting M, Lightning R Rain, et al. Kikiskawâwasow - prenatal healthcare provider perceptions of effective care for First Nations women: An ethnographic community-based participatory research study. BMC Pregnancy Childbirth. 2016;16(1):216. 9. Oster RT, Bruno G, Mayan MJ, Toth EL, Bell RC; and the ENRICH First Nations Community Advisory Committee Peyakohewamak-Needs of Involved Nehiyaw (Cree) Fathers Supporting Their Partners During Pregnancy: Findings From the ENRICH Study. Qual Health Res. 2018;1049732318794205 [Epub ahead of print]. 10. Wiebe AD, Barton S, Auger L, Pijl-Zieber E, Foster-Boucher C. Restoring the blessings of the morning star: Childbirth and maternal-infant health for First Nations near Edmonton, Alberta. Aboriginal Policy Studies. 2015; 5(1):4768 11. Holkup PA, Tripp-Reimer T, Salois EM, Weinert C. Community-based participatory research: an approach to intervention research with a Native American community. ANS Adv Nurs Sci. 2004 ;7(3):162175. 12. Wallerstein NB, Duran B. Using community-based participatory research to address health disparities. Health Promot Pract. 2006;7(3):312-23. 13. Kyoon-Achan G, Lavoie J, Avery Kinew K, PhillipsBeck W, Ibrahim N, Sinclair S, et al. Innovating for transformation in First Nations Health using community-based participatory research. Qualitative Health Research. 2018;28(7):1036-49. 14. Neergaard 
MA, Olesen F, Andersen RS, Sondergaard J. Qualitative description - the poor cousin of health research? BMC Med Res Methodol. 2009;9(52):52. 15. Sandelowski M. What's in a name? Qualitative description revisited. Res Nurs Health. 2010;33(1):77-84. 16. Mayan MJ. Essentials of Qualitative Inquiry. Walnut Creek, CA: Left Coast Press, Inc; 2009. p. 85-99. 17. Canadian Institutes of Health Research, Natural Sciences and Engineering Research Council of Canada, \& Social Sciences and Humanities Research Council of Canada. Tri-Council Policy Statement: Ethical Conduct for Research Involving Humans. Chapter 9: Research Involving the First Nations, Inuit and Métis Peoples of Canada. 2014 http://www.pre.ethics.gc.ca/pdf/eng/tcps2-2014/TCPS_2_FINAL_Web.pdf. Accessed 12 September 2018. 18. Whittemore R, Chase SK, Mandle CL. Validity in qualitative research. Qual Health Res. 2001;11(4):522-37. 19. Milne J, Oberle K. Enhancing rigor in qualitative description: A case study. J Wound Ostomy Continence Nurs. 2005;32(6):413-20. 20. Stielgelbauer SM. What is an Elder? What do Elders do? First Nations Elders as teachers in culture-based urban organizations. Can J Native Stud. 1996;16(1):37-66. 21. Auger M, Howell T, Gomes T. Moving toward holistic wellness, empowerment and self-determination for Indigenous peoples in Canada: Can traditional Indigenous health care practices increase ownership over health and health care decisions? Can J Public Health. 2016;27:107(4-5):e393-8. 22. Puchala C, Paul S, Kennedy C, Mehl-Madrona L. Using traditional spirituality to reduce domestic violence within aboriginal communities. J Altern Complement Med. 2010;16:89-96 23. Hadjipavlou G, Varcoe C, Tu D, Dehoney J, Price R, Browne AJ. "All my relations": Experiences and perceptions of Indigenous patients connecting with Indigenous Elders in an inner city primary care partnership for mental health and well-being. CMAJ. 2018;190(20):E608-15. 24. Kolahdooz F, Launier K, Nader F, June K, Baker P McHugh TL, et al. Canadian Indigenous women's perspectives of maternal health and health care services: A systematic review. Divers Equal Health Care. 2016;13(5):334-48. 25. Oster RT, Mayan MJ, Toth EL. Diabetes in pregnancy among First Nations women. Qual Health Res. 2014;24(11):1469-80. 26. Sokoloski EH. Canadian First Nations women's beliefs about pregnancy and prenatal care. Can J Nurs Res. 1995;27(1):89-100. 27. Heaman MI, Sword W, Elliott L, Moffatt M, Helewa ME, Morris H, et al. Perceptions of barriers, facilitators and motivators related to use of prenatal care: A qualitative descriptive study of inner-city women in Winnipeg. SAGE Open Med. 2015;3:2050312115621314. 28. Smith P. Commentary: A settler physician perspective on Indigenous health, truth, and reconciliation. Can Med Educ J. 2018;9(3):e101-8. 29. Baba L. Cultural safety in First Nations, Inuit and Métis public health: Environmental scan of cultural competency and safety in education, training and health services. Prince George, BC: National Collaborating Centre for Aboriginal Health; 2013. 30. Heaman MI, Sword W, Elliott L, Moffatt $M$, Helewa ME, Morris $H$, et al. Barriers and facilitators related to use of prenatal care by inner-city women: Perceptions of health care providers. BMC Pregnancy Childbirth. 2015;15(1):2. 31. Wiebe AD, Barton S, Auger L, Pijl-Zieber E, Foster-Boucher C. Restoring the blessings of the morning star: Childbirth and maternal-infant health for First Nations near Edmonton, Alberta. Aboriginal Policy Studies. 2015;5(1):47-68. 32. Tait Neufeld H. Patient and caregiver perspectives of health provision practices for First Nations and Métis women with gestational diabetes mellitus accessing care in Winnipeg, Manitoba. BMC Health Serv Res. 2014;14(1):440. 33. McGough S, Wynaden D, Wright M. Experience of providing cultural safety in mental health to Aboriginal patients: A grounded theory study. Int J Ment Health Nurs. 2018;27(1):204-13. 34. Chandler MJ, Lalonde C. Cultural continuity as a hedge against suicide in 
Canada's First Nations. Transcult Psychiatry. 1998;35(2):191-219. 35. Oster RT, Grier A, Lightning R, Mayan MJ, Toth EL. Cultural continuity, traditional Indigenous language, and diabetes in Alberta First Nations: a mixed methods study. Int J Equity Health. 2014;13:92. 36. Gone JP. Redressing First Nations historical trauma: theorizing mechanisms for Indigenous culture as mental health treatment. Transcult Psychiatry. 2013;50(5):683-706. 37. Auger MD. Cultural continuity as a determinant of indigenous peoples' health: A metasynthesis of qualitative research in Canada and the United States cultural continuity as a determinant of indigenous peoples' health. Int Indig Policy J. 2016;7 (4):3. 38. Rowan M, Poole N, Shea B, Gone JP, Mykota D, Farag M, et al. Cultural interventions to treat addictions in Indigenous populations: findings from a scoping study. Subst Abuse Treat Prev Policy. 2014;9:34. 39. Chen L, Xiao L, Auger N, Torrie J, McHugh NG, Zoungrana H, et al. Disparities and trends in birth outcomes, perinatal and infant mortality in Aboriginal vs. non-Aboriginal populations: A population-based study in Quebec, Canada 1996-2010. PLoS One. 2015;10(9):e0138562. 40. Xavier CG, Brown HK, Benoit AC. Teenage pregnancy and long-term mental health outcomes among Indigenous women in Canada. Arch Womens Ment Health. 2018;21(3):333-40. 41. Daniels S, Robson D, Flatley C, Kumar S. Demographic characteristics and pregnancy outcomes in adolescents - Experience from an Australian perinatal centre. Aust N Z J Obstet Gynaecol. 2017;57(6):630-35. 42. Innes RA, Andersen K. Indigenous men and masculinities: Legacies, identities, regeneration. Winnipeg, MN: University of Manitoba Press; 2015. 43. Ball J. Fathering in the shadows: Indigenous fathers and Canada's colonial legacies. Ann Am Acad Pol Soc Sci. 2009;624(1):29-48. 44. Ball J. Indigenous fathers' involvement in reconstituting "circles of care". Am J Community Psychol. 2010;45(1-2):124-38. 45. Durey A, McEvoy S, Swift-Otero V, Taylor K, Katzenellenbogen J, Bessarab D. Improving healthcare for Aboriginal Australians through effective engagement between community and health services. BMC Health Serv Res. 2016;16:224. 46. Verney SP, Avila M, Espinosa PR, Cholka CB, Benson JG, Baloo A, et al. Culturally sensitive assessments as a strength-based approach to wellness in Native communities: A community-based participatory research project. Am Indian Alsk Native Ment Health Res. 2016;23(3):271-92. 